\title{
Theoretical Exploration and Realization Path of Double Cycle New Development Pattern
}

\author{
Yuantao Jiang * and He Yang \\ School of economics and management, Shanghai Maritime University, Shanghai 201306, China \\ *Corresponding author. Email: xianhetao666@163.com
}

\begin{abstract}
the new development pattern of domestic and international double cycle strategy is an important strategic measure of the new development pattern put forward by China under the background of over reliance on the international large cycle model. However, at present, there are different understandings about the connotation of double cycle, and there is also a vague understanding of the relationship between domestic cycle and international cycle, which is not conducive to the smooth implementation of the new development pattern of double cycle. This paper reviews and analyses the relevant research status of economic double cycle, theoretically explores the internal logic of domestic and international double cycle strategy, analyses the interaction between domestic cycle and international cycle, further constructs the realization path of the new development pattern strategy of double cycle, and makes an empirical analysis by using structural equation model.
\end{abstract}

Keywords: Double cycle strategy, Domestic circulation, Structural equation model.

\section{INTRODUCTION}

Since the reform and opening up, the Chinese government has implemented the "international big cycle" economic development strategy, expanded the economic operation from domestic cycle to international cycle, and achieved great historic success. However, the current global economic growth is blocked, and Sino US economic and trade frictions and the outbreak of COVID-19 have made structural changes in China's economy and external environment. Under the current situation, the Chinese government puts forward a new development pattern of "double cycle" in which domestic and international double cycles promote each other to deal with the new development environment at home and abroad.

The existing literature on "double cycle" mainly focuses on the theoretical level. Zhen Li et al. (2021) summarized the historical process of circular interaction at home and abroad, and believed that innovation is the strategic focus of unblocking the circular interaction at home and abroad [1]. Zhiyong Dong and Chengming Li (2020) proposed that the formation of a new development pattern should focus on unblocking the domestic circulation [2]. Bei Jin (2021) discussed the necessity of forming a "double cycle" new development pattern in order to achieve the security and stability of
China's economic development from the perspective of national security [3].

The existing literature has a thorough theoretical research on the new development pattern of double cycle, but most studies discuss the theoretical basis of double cycle, the importance of double cycle development pattern and how to realize double cycle development pattern through theoretical analysis methods. Few literatures empirically analyze the realization path of the new double cycle development pattern through econometric methods. Therefore, this paper theoretically analyzes the relationship between the two cycles, constructs the realization path of the new development pattern, empirically analyzes the realization path of the two cycles by using the structural equation model, and analyzes the specific impact of each link of the realization path of the two cycles in detail.

\section{THEORETICAL EXPLORATION}

Economic cycle includes different links such as production, investment, exchange, distribution and consumption. From the perspective of domestic cycle, domestic production mainly refers to the activities of domestic production enterprises to convert input into output, or the activities of combining production factors 
to manufacture products. The main purpose of domestic production is to supply domestic consumption and to supply foreign production and consumption. Foreign production mainly refers to the activities that enterprises outside the country convert input into output. The main purpose of foreign production is to supply foreign consumption and to supply domestic production and consumption. Investment is the foundation of production. Domestic investment mainly refers to the investment activities carried out by the local government, enterprises and individuals in the country. Investment is the carrier of technological progress, and any application of technological achievements must be reflected through some kind of investment activities. Any technological achievement is the product of investing certain capital and resources. The main purpose of domestic investment is to provide various production factors and technologies to domestic production and convert them into products. Foreign investment mainly refers to the investment activities carried out by foreign governments, enterprises and individuals outside their own countries. The main purpose of foreign investment is to provide various production factors and technologies to foreign production and convert them into products. Domestic consumption is a process in which domestic governments, enterprises and individuals use social products to meet their own needs.

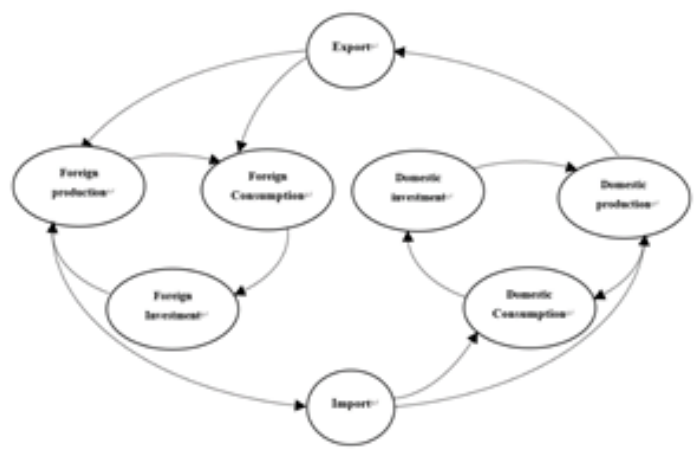

Figure 1 Domestic and international "double cycle" development pattern

Based on the relationship between production, investment and consumption, this paper constructs the double cycle path relationship between domestic and international large cycle from the perspective of domestic and international double cycle, as shown in Figure 1. Among them, domestic products are the key point of the whole big cycle. It not only promotes domestic consumption, but also drives the export of international trade. Domestic consumption is conducive to the domestic investment, and domestic investment is further used to promote the domestic production. Therefore, domestic production, consumption and investment constitute three paths, forming a domestic cycle. Domestic production is conducive to the export.
The exported products not only directly affect foreign consumption, but also provide guarantee for foreign production. Foreign consumption also promotes foreign investment, which is conducive to foreign production. The products produced abroad drive the import link, and the import is finally used for domestic production and domestic consumption. Therefore, import, foreign production, consumption, investment and import constitute an international cycle. The domestic cycle and the international cycle together constitute a new development pattern of "double cycle".

\section{PATH CONSTRUCTION AND RELATED ASSUMPTIONS}

As an important part of China's GDP, export can directly drive GDP growth. The increase of exports means the increase of foreign demand, driving the increase of domestic production and supplying more products for foreign production and consumption. Bonai Fan et al. (2005) found that China's export trade is an important reason to promote China's GDP growth by using generalized differential regression and ganger causality model [4]. Therefore, the following assumptions are made.

Hypothesis H1: export has a significant positive impact on production

The increase in exports will lead to an increase in the average wage level of relevant employed persons and an increase in the disposable income of domestic consumers. Xiaojuan Jiang and Lijun Meng (2021) pointed out that China's export industries are mainly concentrated in labor-intensive products and processing links, so the employment absorption capacity of export industries is stronger than that of mainland industries [5]. Chuanchuan Zhang (2015) empirically estimated the impact of export on employment and wages, and found that export growth significantly improved the employment level of manufacturing and service industries and the income level of relevant practitioners [6]. Therefore, the following assumptions are made based on the above theoretical basis

Hypothesis H2: export has a significant positive impact on income

Income is the most fundamental factor affecting consumer demand and the endogenous driving force of consumption. When the income changes, the consumer demand for a commodity and even the consumption expenditure structure will change. With the continuous increase of income, consumers' consumption level will continue to upgrade. From an empirical point of view, Minna Ma and Lihuan Guo (2011) analyzed the income and consumption of urban and rural residents in China from 1978 to 2009 by using cointegration theory and error correction model, and found that in the long run, the income of urban and rural residents has a great 
impact on consumption [7]. Therefore, the following assumptions are made based on the above theoretical basis

Hypothesis H3: income has a significant positive impact on consumption

Yinxing Hong (2013) pointed out that expanding consumption to stimulate economic growth meets the Marxist concept of consumption [8]. The development of consumption promotes the development of production. The new needs formed by consumption play a guiding role in the adjustment and upgrading of production. Product upgrading is the specific manifestation of consumption upgrading. Yangyang $\mathrm{Hu}$ and Tongquan Zhang (2018) found that the material consumption demand of urban and rural residents in China has a significant impact on the cultural consumption demand through the empirical analysis of establishing the distribution lag model, that is, Maslow's demand hierarchy theory is applicable to the cultural consumption behavior of urban and rural residents in China [9]. Maslow's demand theory points out that human need can be divided from low to high. When consumers meet their basic needs, they will pursue high-level needs. With the increasing consumption, manufacturers will supply more diversified and high-quality products and services to meet the upgraded consumption demand by increasing production, upgrading and importing products and services. Therefore, the following assumptions are made

Hypothesis H4: consumption has a significant positive impact on production

Hypothesis H5: consumption has a significant positive impact on upgrading

Upgrading refers to the innovative changes in technology, materials and processes of commercial products. Upgrading is often accompanied by technological progress. Wei Liu and Hui Zhang (2008) pointed out that the role of technological progress in promoting the economy should not be ignored, and most of the current studies on the specific impact mechanism of this role are analysed at the macro level [10]. Weiqing $\mathrm{Li}$ and Xianzhong Nie (2015) believe that industrial upgrading can drive demand expansion, promote enterprises to achieve technological progress, guide regions to increase research and development investment and promote regional economic development [11]. Technological progress promotes the division of labor in production, which improves work efficiency, productivity and production. Therefore, the following assumptions are made based on the above theoretical basis

Hypothesis H6: upgrading has a significant positive impact on production
Based on the hypothetical analysis of the above six aspects, the realization path of the new double cycle development pattern is constructed, as shown in Figure 2 .

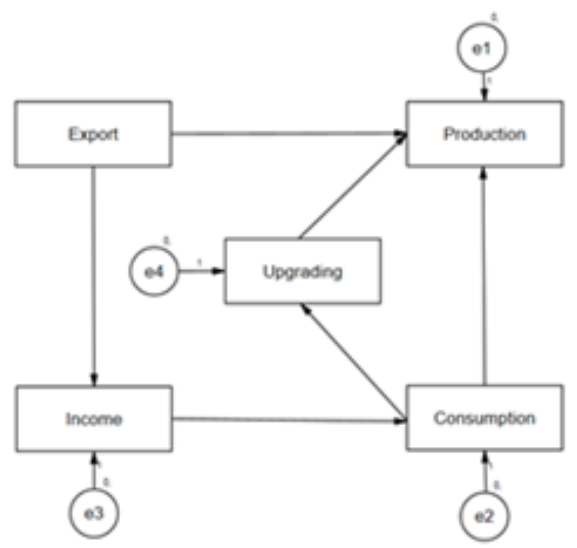

Figure 2 Implementation path of new development pattern of double cycle

The most important thing of the new development pattern of double cycle based on domestic large cycle is to give play to the driving effect of internal cycle on economy. Therefore, this paper constructs the realization path of the new development pattern of double cycle based on internal cycle. Among them, production is the direct embodiment of sustainable economic development. This paper holds that consumption not only directly promotes the increase of production, but also indirectly promotes the growth of production by affecting industrial and technological upgrading. As a key node connecting the internal and external circulation, export also has a positive impact on production. Export also indirectly affects production by increasing the income of residents or departments and enhancing the consumption capacity.

\section{EMPIRICAL ANALYSIS PROCESS}

\subsection{Data Source and Processing}

In this paper, the flow link of double cycle is simplified, and the structural equation model includes the following measurement variables: income, consumption, production, export and upgrading. The model data are all public statistical data, so it can not include latent variables. Among them, income, consumption, production, export and upgrading are measured by per capita disposable income, per capita total retail sales of consumer goods, per capita GDP, per capita export and the number of domestic patent applications. The export data comes from the 2021 monthly statistical report published on the official website of the General Administration of Customs of the people's Republic of China. All other data are from the annual data released on the official website of the National Bureau of statistics. The data are officially 
released statistical data and belong to objective data. Therefore, the reliability and validity of the obtained data will not be tested. Because the concepts of the selected data are similar, the data are standardized and logarithmic processing is adopted for the data. Among them, the ratio of China's GDP to the current year's population from 1995 to 2020 is taken as the data of per capita GDP, the ratio of China's total retail sales of social consumer goods to the current year's population from 1995 to 2020 is taken as the data of per capita consumption, and the ratio of China's total export to the current year's population from 1995 to 2020 is taken as the data of per capita export, Since China used a new statistical method of per capita disposable income in 2013, this paper adopts:

$\frac{\text { PCDI }_{U}{ }_{t} \times \text { Population }_{U} t+P C D I_{R}{ }_{t} \times \text { Population }_{R t} t}{\text { Population }}$

In formula (1), $\boldsymbol{P C D I _ { \boldsymbol { U } } \boldsymbol { t }}$ represents the per capita disposable income of urban residents in the current year, $\boldsymbol{P C D I}_{R_{t} t}$ represents the per capita net income of rural households in the current year, Population $\boldsymbol{t}_{\boldsymbol{t}}$ represents the total urban population in the current year, Population $_{R} \boldsymbol{t}$ represents the total rural population in the current year, and Population $\boldsymbol{t}_{\boldsymbol{t}}$ represents the total population in the current year. The data calculated by this formula replace the data of per capita disposable income from 1995 to 2012. The measurement variable of production is the logarithm of per capita GDP Based on natural logarithm e (the same below); The measurement variable of consumption is the logarithm of social per capita consumption; The measurement variable of export is the logarithm of per capita export, the measurement variable of upgrading is the logarithm of the number of domestic patent applications authorized over the years, and the measurement variable of income is the logarithm of China's per capita disposable income. Use spss26.0 to input all the above data.

\subsection{Identification Test of Structural Equation}

Xiaodi Li and Jiating Chen (2014) used the identifiable test rule $t$ rule to test the structural equation model, and considered that $\mathrm{t}$ rule is a necessary condition for model identification [12]. Therefore, this paper also adopts $\mathrm{t}$ rule to test the identifiability of structural equation model. The formula is as follows:

$$
\begin{aligned}
& \mathbf{t} \leq \\
& \frac{(m+n)(m+n+1)}{2}
\end{aligned}
$$

In formula (2): there are $\mathrm{m}+\mathrm{n}$ measurement variables, and $\mathrm{t}$ is the number of freely estimated parameters in the model. In the model constructed in this paper, there are 16 different parameters to be estimated, that is, $\mathrm{t}$ is equal to 16 . There are 5 exogenous variables and 4 endogenous variables, $m+n$ equal to $9,(m+n)(m+n+1) / 2=9 \times 10 / 2=45$. It can be seen that the constructed double cycle driving path structural equation model can be identified.

\subsection{Model Estimation Based on Ml Method}

Import the data into Amos 24.0, and use the maximum likelihood estimation method to calculate and estimate the structural equation model. The detailed empirical results are shown in Table 1, and the

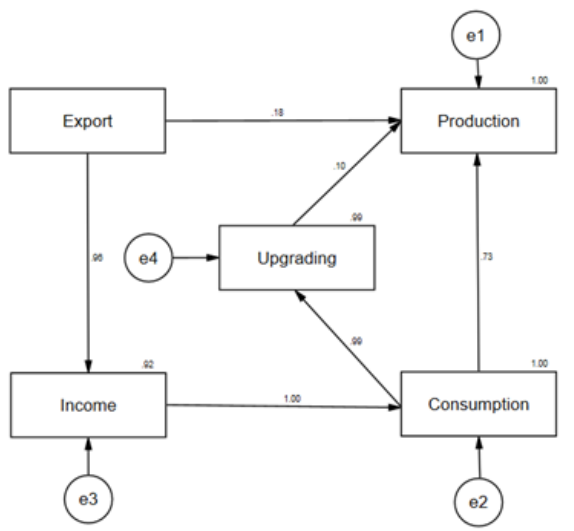

standardized path coefficient is shown in Figure 3.

Figure 3 calculation results of path coefficient of structural equation

\subsection{Hypothesis Test}

It can be seen from table 1 that export has a significant positive impact on income, income has a significant positive impact on consumption, consumption has a significant positive impact on upgrading, export has a significant positive impact on production and consumption has a significant positive impact on production. The five paths are established at the significance level of $1 \%$, and upgrading has a significant positive impact on production, $\mathrm{P}$ value is $0.019<0.05$, the path was established at the $5 \%$ significance level. It is assumed that H1 H6 are verified.

\subsection{Fit Test}

Dennis L. Jackson (2009) summarized the fitting indexes commonly used in previous papers using structural equation models, including the ratio of chi square value to degrees of freedom, the root mean square (RMSEA) of approximation error, and the mean square and square root of standardized residuals (SRMR); Common value-added fitness indicators include comparative fit index (CFI), normative fit index (NFI), incremental fit index (IFI), relative fit index (RFI) and Tucker-Lewis index (TLI) [13]. Therefore, this paper also uses these fitting indexes as the fitting index of this paper. The fitting results of the structural 
equation model constructed in this paper are shown in

Table 1. Path coefficient results

\begin{tabular}{|c|c|c|c|c|c|c|c|c|}
\hline & \multicolumn{2}{|c|}{ Path } & Estimate & S.E. & C.R. & $\mathrm{P}$ & Label & Standardized \\
\hline Income & $<---$ & Export & 0.898 & 0.053 & 16.881 & $* * *$ & par_1 & 0.959 \\
\hline Consumption & $<---$ & Income & 1.074 & 0.009 & 123.572 & $* * *$ & par_5 & 0.999 \\
\hline Upgrading & $<---$ & Consumption & 1.554 & 0.032 & 47.855 & $* * *$ & par_6 & 0.995 \\
\hline Production & $<--$ & Export & 0.176 & 0.014 & 12.645 & $* * *$ & par_2 & 0.179 \\
\hline Production & $<---$ & Consumption & 0.712 & 0.040 & 17.768 & $* * *$ & par_3 & 0.730 \\
\hline Production & $<---$ & Upgrading & 0.061 & 0.026 & 2.352 & 0.019 & par_4 & 0.098 \\
\hline
\end{tabular}

Notes: $* * *$ indicated correlation above were in statistically significant level $(\mathrm{P}<0.01)$

Table 2. Fit test results

\begin{tabular}{|l|l|l|l|l|l|l|l|l|}
\hline Fitting index & $\begin{array}{l}\chi^{2}(\text { Degrees of } \\
\text { freedom })\end{array}$ & RMSEA & SRMR & CFI & NFI & IFI & RFI & TLI \\
\hline value & $16.220(4)$ & 0.350 & 0.002 & 0.977 & 0.970 & 0.977 & 0.926 & 0.943 \\
\hline
\end{tabular}

Among them, the absolute fitness index chi square value is 16.220 , the degree of freedom is 4 , the ratio of chi square value to degree of freedom is 4.055 , which is greater than the recommended value of 1-3 and less than the acceptable value of 5 , and the fitting degree is acceptable. The RMSEA is 0.35 , which is greater than the recommended value of 0.08. David A. Kenny (2015) and Peter M. bentler (1999) pointed out that the small sample structural equation model itself will have the problem of too large RMSEA [14] [15]. Due to the availability of data, it is objectively impossible to avoid the problem that the small sample RMSEA is too large, and the structural equation model data is usually the subjective data obtained from the questionnaire, while the data selected in this article are objective data. Therefore, the adaptability of the structural equation constructed in this paper cannot be rejected because the adaptation index of RMSEA is inconsistent, Instead, you should check the adaptation results of other common fitness indicators and comprehensively consider the model adaptation degree. SRMR is 0.002, less than the recommended value of 0.05 , and the fitting degree is good. The value-added fitness indexes CFI, NFI, IFI, RFI and TLI are greater than the recommended value of 0.9 , and the CFI, NFI and IFI are more than 0.97 , indicating that the model has good fitting. In conclusion, the author believes that the structural equation model constructed in this paper passes the fitting test.
Table 2. 
Table 4. Statistics of indirect effect coefficient

\begin{tabular}{|c|c|c|c|c|}
\hline $\begin{array}{c}\text { Independent } \\
\text { variable } \\
\text { dependent } \\
\text { variable }\end{array}$ & Export & Income & $\begin{array}{c}\text { Consumptio } \\
\mathrm{n}\end{array}$ & $\begin{array}{c}\text { Upgra } \\
\text { ding }\end{array}$ \\
\hline income & 0 & 0 & 0 & 0 \\
\hline consumption & 0.958 & 0 & 0 & 0 \\
\hline upgrading & 0.953 & 0.994 & 0 & 0 \\
\hline production & 0.792 & 0.826 & 0.097 & 0 \\
\hline
\end{tabular}

\subsubsection{Comparison of Direct Effect and Indirect Effect}

The indirect effect of export on production is greater than the direct effect, which shows that the increase of export mainly increases production by increasing income, then increasing consumption. The direct effect of consumption on production is greater than the indirect effect.

\section{CONCLUSION AND ENLIGHTENMENT}

The path coefficient of consumption for the driving path of production is the largest and the promoting effect is the most obvious. The driving effect of export on production is mainly to increase consumption by increasing income. The increase of consumption leads to the increase of production. Upgrading has a driving effect on production, but it is far less obvious than the driving effect of consumption on production.

Therefore, to unblock the domestic big cycle, promote the formation of a new development pattern of double cycle, and realize sustained medium and high-speed economic growth, the most important thing is to improve domestic consumption. One of the most effective ways to promote consumption is to increase residents' income. The Chinese government can achieve the purpose of promoting consumption and unblocking the new development pattern of double circulation by reasonably raising the minimum wage and improving medical, housing, education and pension policies.

\section{REFERENCES}

[1] Zhen Li, Zhongze Chang, Wei Dai. Double cycle mutual promotion: theoretical logic, strategic focus and policy orientation $[\mathrm{J}]$. Shanghai Journal of Economics, 2021 (04): 16-27

[2] Zhiyong Dong, Chengming Li. New development pattern of domestic and international double cycle: Historical Tracing, logical interpretation and policy guidance $[\mathrm{J}]$. Journal of the Party School of the Central Committee of the C.P.C. (Chinese Academy of Governance), 2020,24 (05): 47-55

[3] Bei Jin. Building a new development pattern of double cycle and opening a new journey of China's economy [J]. Regional Economic Review, 2021 (01): 5-9

[4] Bonai Fan, Xiaotai Mao, Shuang Wang. Empirical Study on the contribution rate of China's export trade to economic growth: 1952-2003 [J]. Journal of International Trade, 2005 (08): 5-9

[5] Xiaojuan Jiang, Lijun Meng. Focusing on internal circulation, enabling external circulation and higher-level double circulation -- international experience and Chinese practice $[\mathrm{J}]$. Management World, 2021,37 (01): 1-19

[6] Chuanchuan Zhang. The impact of export on employment, wage and income inequality -evidence based on micro data $[\mathrm{J}]$. China Economic Quarterly, 2015,14 (04): 1611-1630

[7] Minna Ma, Lihuan Guo. Empirical analysis on long-term equilibrium and short-term fluctuation of income and consumption of urban and rural residents in China [J]. Statistics \& Decision, 2011 (03): $125-127$

[8] Yinxing Hong. Consumption demand, consumption power, consumption economy and economic growth $[\mathrm{J}]$. China Economic Studies, 2013 (01): 3-8

[9] Yangyang $\mathrm{Hu}$, Tongquan Zhang. Study on the differences and influencing factors of cultural consumption of urban and rural residents in China -- a distribution lag model based on Maslow's hierarchy of demand theory $[\mathrm{J}]$. Journal of Commercial Economics, 2018 (13): 51-54

[10] Wei Liu, Hui Zhang. Industrial structure change and technological progress in China's economic growth [J]. Economic Research Journal, 2008,43 (11): $4-15$

[11] Weiqing Li, Xianzhong Nie. Industrial upgrading and independent innovation: mechanism analysis and empirical research [J]. Studies in Science of Science, 2015,33 (07): 1008-1016

[12] Xiaodi Li, Jiating Chen. Research on the driving path of FDI to the evolution of regional innovation system -- Analysis Based on structural equation model [J]. Science of Science and Management of S.\& T., 2014,35 (08): 39-48

[13] Jackson, Dennis \&amp; Gillaspy, Art \&amp; Purc-Stephenson, Rebecca. (2009). Reporting Practices in Confirmatory Factor Analysis: An Overview and Some Recommendations. Psychological methods, 14(1), 6-23.

[14] Kenny, D. A., Kaniskan, B., \&amp; McCoach, D. B. (2015). The Performance of RMSEA in Models 
with Small Degrees of Freedom. Sociological Methods \&amp; Research, 44(3), 486-507.

[15] Bentler, Peter \& amp; Yuan, Ke-Hai. (1999). Structural Equation Modeling with Small Samples: Test Statistics. Multivariate Behavioral Research, 34(2), 181-197. 